\title{
Synthesis of Carbon Nanofibers with Maghemite via a Modified Sol-Gel Technique
}

\author{
Nicolás Díaz Silva, ${ }^{1}$ Benjamín Valdez Salas, ${ }^{1}$ Nicola Nedev, ${ }^{1}$ Mario Curiel Alvarez, \\ José M. Bastidas Rull, ${ }^{2}$ Roumen Zlatev, ${ }^{1}$ and Margarita Stoytcheva ${ }^{1}$ \\ ${ }^{1}$ Engineering Institute, Autonomous University of Baja California, 21100 Mexicali, BC, Mexico \\ ${ }^{2}$ Centro Nacional de Investigaciones Metalúrgicas (CENIM), CSIC, Avda. Gregorio del Amo 8, 28040 Madrid, Spain \\ Correspondence should be addressed to Benjamín Valdez Salas; benval@uabc.edu.mx
}

Received 11 July 2017; Accepted 31 July 2017; Published 9 November 2017

Academic Editor: Andrew R. Barron

Copyright ( 2017 Nicolás Díaz Silva et al. This is an open access article distributed under the Creative Commons Attribution License, which permits unrestricted use, distribution, and reproduction in any medium, provided the original work is properly cited.

Carbon nanohybrid material $\left(\mathrm{CNF} / \gamma-\mathrm{Fe}_{2} \mathrm{O}_{3}\right)$ was obtained via a modified sol-gel technique consisting of two steps: functionalization of carbon nanofibers (CNF) in $\mathrm{H}_{2} \mathrm{SO}_{4} / \mathrm{HNO}_{3}$ followed by synthesis using $\mathrm{Fe}\left(\mathrm{NO}_{3}\right)_{3} \bullet 9 \mathrm{H}_{2} \mathrm{O}$. As a result, the iron content of the $\mathrm{CNF} / \gamma-\mathrm{Fe}_{2} \mathrm{O}_{3}$ was increased by more than twice from about $40 \%$ to about $87 \%$ mass percent, compared to the pristine $\mathrm{CNF}$ and oxidized CNF specimens, as proved by energy dispersive X-ray fluorescence. Scanning electron microscopy images exhibited "cumulus" on the $\mathrm{CNF} / \gamma-\mathrm{Fe}_{2} \mathrm{O}_{3}$ specimen surface, which showed the highest iron mass percentage, proved by energy dispersive $\mathrm{X}$-ray spectroscopy. Transmission electron microscopy images confirmed attachment of $\gamma-\mathrm{Fe}_{2} \mathrm{O}_{3}$ cumulus to the inner and outer surfaces of the CNF walls after synthesis. The characteristic peaks of $\mathrm{Fe} 2 \mathrm{p}_{3 / 2}$ and Fe $2 \mathrm{p}_{1 / 2}$ appeared in the XPS spectra obtained on $\mathrm{CNF} / \gamma-\mathrm{Fe}_{2} \mathrm{O}_{3}$. In addition, X-ray diffraction (XRD) results indicated formation of $\gamma-\mathrm{Fe}_{2} \mathrm{O}_{3}$ during the synthesis process. The Raman spectrum of the $\mathrm{CNF} / \gamma-\mathrm{Fe}_{2} \mathrm{O}_{3}$ sample displays peaks with positions close to characteristic peaks of highly crystalline and monodisperse maghemite nanocrystallites. The synthesis of $\mathrm{CNF} / \gamma-\mathrm{Fe}_{2} \mathrm{O}_{3}$ leads to an increase in the hydrophilicity of CNF and magnetic properties at room temperature.

\section{Introduction}

In recent years, carbon nanofibers (CNFs) have been implemented in a wide variety of applications from aerospace materials as reinforcement or conductive fillers, used to improve the mechanical, electrical, and thermal properties of polymer matrix composites to energy industry as anode materials for applications in Li-ion batteries to improve energy storage properties and life-cycle. CNFs, as well as the multiwalled nanotubes (MWNTs) and the singlewalled nanotubes (SWNTs), are the most common components of the nanocomposites [1-15]. Industrial products made of reinforced polymers demand improvement of the mechanical properties to preserve the structural integrity and the electrical conductivity to dissipate static electricity [16]. However, the above-mentioned carbon nanostructures differ considerably in terms of morphology, size, and price. Applied Sciences, Inc. (ASI) has performed a study which reports the advantages of using CNFs instead of CNTs. Stacked-cup carbon nanotubes, also known as CNFs, have a structure, which consists of graphene layers stacked in conic sections with walls angled $20^{\circ}$ along the axis of the fiber. This structure provides exposed edge planes on the interior and exterior surfaces of the fiber, which promotes the chemical functionalization. In contrast, the CNT consists of an assembly of concentric cylinders of graphene. CNFs typically have a few tens of microns length and diameters from 30 to $100 \mathrm{~nm}$ with an aspect ratio greater than 100. On the other hand, CNTs typically have smaller diameters and lengths in comparison with CNF. CNFs can be commercially available at a much lower cost and high volumes in comparison with CNTs. The CNF material is easy to handle and overcomes all the main challenges resulting from dispersion, processing, and handling normally associated with other carbon nanomaterials (CNMs) [1720]. The CNF material is considered as a reinforcement 
or conductive nanofiller for preparation of composites due to the nanofiber mechanical (tensile strength $\sim 3 \mathrm{GPa}$ ), and physical properties (electrical conductivity $\sim 103 \mathrm{~S} / \mathrm{cm}$ ) [21].

The alignment and dispersion of the CNFs in the matrix are the main challenges to obtain the desired properties. These challenges can be overcome by changing the CNFs chemical composition to create a nanohybrid material with unique characteristics, which allow easy handling. It has been reported that functionalized carbon nanofibers can be aligned in composite materials using AC electric field, which leads to significant decrease of the electrical resistivity in the direction of the aligned CNFs and to increase of the compressive modulus and compressive strength [22]. It is well known that a magnetic field may align small and light objects parallel to that field. Therefore, the use of nanohybrid material with magnetic properties in a polymer matrix composite can significantly enhance the composite structure properties through alignment of the nanomaterial in the polymeric matrix by magnetic field during the material processing. The fabrication of carbon nanohybrid materials composed with metal oxides has been widely studied implementing the use of different techniques such as electrospinning followed by a thermal treatment and modified sol-gel. Previous researches have reported the application of electrospinning technique to fabricate $\mathrm{CNF} / \gamma-\mathrm{Fe}_{2} \mathrm{O}_{3}$ for $\mathrm{Li}$-ion batteries as high performance anode material. On the other hand, the use of modified sol-gel technique has also been reported using MWCNTs as the base to create a nanohybrid material in order to improve the material properties of polymers [815, 23-25]. Nevertheless, no researches have been reported about the implementation of the same technique using CNFs, which could result in better synthesis results due to the CNF's morphology, in addition to the low cost of the nanohybrid material. CNFs have been functionalized with magnetite $\left(\mathrm{Fe}_{3} \mathrm{O}_{4}\right)$ by a coprecipitation method in order to align them in an epoxy matrix, resulting in a higher electrical conductivity along the direction of the alignment [26]. Maghemite, $\gamma$ $\mathrm{Fe}_{2} \mathrm{O}_{3}$, is a member of the same iron oxide family as magnetite $\left(\mathrm{Fe}_{3} \mathrm{O}_{4}\right)$ and the main difference between these two oxides is the presence of only ferric $\left(\mathrm{Fe}^{3+}\right)$ ions in the maghemite allotropic form, while both ferrous $\left(\mathrm{Fe}^{2+}\right)$ and $\mathrm{Fe}^{3+}$ ions are found in magnetite. Maghemite cannot be oxidized at normal operation conditions and is more stable than magnetite; moreover, it has ferromagnetic properties and can be used to impart magnetic properties in functionalized CNFs. In this work, we describe the synthesis of maghemite carbon nanofibers $\left(\mathrm{CNF} / \gamma-\mathrm{Fe}_{2} \mathrm{O}_{3}\right)$ via a modified sol-gel technique applying an iron salt as a precursor, followed by calcination.

The resulting nanohybrid material was characterized and compared to the starting CNFs and oxidized CNF materials using dispersion analysis, magnetism exposure, energy dispersive X-ray fluorescence (EDXRF), scanning electron microscopy (SEM) with energy dispersive $\mathrm{X}$-ray spectroscopy (EDS), transmission electron microscopy (TEM), $\mathrm{X}$-ray photoelectron spectroscopy (XPS) X-ray diffraction (XRD), and Raman spectroscopy.
TABLE 1: Carbon nanofiber properties.

\begin{tabular}{lc}
\hline Parameter & Quantity \\
\hline Fiber diameter, nm & $\approx 100$ \\
CVD carbon overcoat present on fiber & Slight \\
Surface area, m2/g & 45 \\
Dispersive surface energy, mJ/m2 & 85 \\
Moisture, wt.\% & $<5$ \\
Iron, ppm & $<14,000$ \\
Polyaromatic hydrocarbons, mg PAH/mg Fiber & $<1$ \\
Surface area, m2/g & Slight \\
\hline
\end{tabular}

\section{Materials and Methods}

2.1. Materials. The CNFs used in this study were Pyrograf PR-24-XT-PS from Applied Sciences, Inc. According to the specifications, these CNFs have an average diameter of about $100 \mathrm{~nm}$ and a minimal chemically vapor deposited (CVD) layer of carbon on the surface of the fiber over a graphitic tubular core. The CNF properties are shown in Table 1. The chemicals used for the synthesis of $\mathrm{CNF} / \gamma$ $\mathrm{Fe}_{2} \mathrm{O}_{3}$, such as propylene oxide, iron (III) nitrate nonahydrate $\left(\mathrm{Fe}\left(\mathrm{NO}_{3}\right)_{3} \bullet 9 \mathrm{H}_{2} \mathrm{O}\right)$, and sulfuric and nitric acid, were purchased from Valrep, SA de CV and used as received.

2.2. Functionalization. CNFs were immersed in a mixture of $\mathrm{H}_{2} \mathrm{SO}_{4} / \mathrm{HNO}_{3}(3: 1)$ at room temperature. The mixture was gently homogenized by magnetic stirring for $5 \mathrm{~min}$ followed by $3 \mathrm{~h}$ in an ultrasonic bath and upheld for $24 \mathrm{~h}$. The mixture was then 50\% diluted with deionized water and filtered with a $0.20 \mu \mathrm{m}$ polytetrafluoroethylene (PTFE) membrane with the aid of a vacuum pump. The oxidized CNFs (CNF-COOH) were rinsed in deionized water until reaching $\mathrm{pH} 5.5$ and dried overnight under a vacuum at $50^{\circ} \mathrm{C}$ [27-33].

2.3. Synthesis of CNF $/ \gamma-\mathrm{Fe}_{2} \mathrm{O}_{3}$. Synthesis of the $\mathrm{CNF} / \gamma-\mathrm{Fe}_{2} \mathrm{O}_{3}$ was performed by first adding $0.65 \mathrm{~g}$ of $\mathrm{Fe}\left(\mathrm{NO}_{3}\right)_{3} \bullet 9 \mathrm{H}_{2} \mathrm{O}$ to $20 \mathrm{ml}$ of ethanol and magnetic stirring until the $\mathrm{Fe}\left(\mathrm{NO}_{3}\right)_{3} \cdot 9 \mathrm{H}_{2} \mathrm{O}$ was dissolved completely. The iron salt solution was then added to a suspension of oxidized $\mathrm{CNF}$ (CNF-COOH) with a mass ratio of $4: 1$ $\left(\mathrm{Fe}\left(\mathrm{NO}_{3}\right)_{3} \bullet 9 \mathrm{H}_{2} \mathrm{O}: \mathrm{CNF}\right)$, stirred, and sonicated for $90 \mathrm{~min} .20 \mathrm{~mL}$ of $1.2 \mathrm{mM}$ sodium dodecylbenzenesulfonate (NaDDBS) was added to the solution and stirred for $30 \mathrm{~min}$. Then $1.2 \mathrm{~mL}$ of propylene oxide was added and the stirring continued for $30 \mathrm{~min}$. The resulting mixture remained in an oven for 3 days at $100^{\circ} \mathrm{C}$. The powder was repeatedly centrifuged at $7000 \mathrm{rpm}$, for $5 \mathrm{~min}$ each time, to reach the ethanol $\mathrm{pH}$. After this, the powder was dried overnight at $50^{\circ} \mathrm{C}$. As a final step, the powder was calcined in a furnace under an argon atmosphere at both $500^{\circ} \mathrm{C}$ and $600^{\circ} \mathrm{C}$ for $2 \mathrm{~h}$.

Electrospinning technique followed by a thermal treatment is the simplest low cost method for fabrication of CNFs at scalable rate. The fabrication of $\mathrm{CNF} / \gamma-\mathrm{Fe}_{2} \mathrm{O}_{3}$ with outstanding results has been demonstrated by other researches in which $\gamma-\mathrm{Fe}_{2} \mathrm{O}_{3}$ is attached to the CNFs outer surface [9]. Nevertheless, electrospinning technique will result in 
TABLE 2: EDS mass percentage results of $\mathrm{CNF} / \gamma-\mathrm{Fe}_{2} \mathrm{O}_{3}$ specimen.

\begin{tabular}{|c|c|c|c|c|c|c|}
\hline Spectrum & Carbon $(\mathrm{C})$ & Oxygen $(\mathrm{O})$ & Iron $(\mathrm{Fe})$ & Phosphorus (P) & Sulfur (S) & Sodium $(\mathrm{Na})$ \\
\hline 1 & 44.06 & 12.51 & 25.33 & 1.19 & 2.73 & 4 \\
\hline 2 & 36.22 & 27.33 & 45.17 & 1.66 & 4.23 & 7.97 \\
\hline 3 & 41.8 & 12.11 & 27.92 & 1.24 & 2.89 & 4.15 \\
\hline 4 & 52.49 & 27.84 & 51.32 & 1.06 & 2.58 & 4.71 \\
\hline Mean mass (\%) & 43.6425 & 19.947 & 37.435 & 1.2875 & 3.1075 & 5.2075 \\
\hline Sigma & 6.7563 & 8.8230 & 12.7761 & 0.2597 & 0.7590 & 1.8668 \\
\hline
\end{tabular}

CNFs with a specific morphology (solid fibers) [10]. On the other hand, the use of sol-gel technique has the flexibility to be implemented in different carbon nanomaterials (CNMs) which could bring different results depending on the CNMs used due to differences in morphology allowing the attachment of metal oxides during the synthesis on the inner and outer surfaces of the CNMs in the case of hollow CNFs.

2.4. Characterization Techniques. The elemental composition was analyzed by EDXRF using a Shimadzu EDX-7000. EDS was performed using a Tescan Lyra 3 XMU scanning electron microscope and the chemical composition was determined by XPS using a SPECS high resolution spectrometer with a $\mathrm{Mg} \mathrm{K} \alpha 1.2(h \nu=1253.6 \mathrm{eV})$ anode $\mathrm{X}$-ray source operated at $15 \mathrm{kV}$ and an emission current intensity of $20 \mathrm{~mA}$, respectively. Three specimens were prepared for each analysis, CNF, $\mathrm{CNF}-\mathrm{COOH}$, and $\mathrm{CNF} / \gamma-\mathrm{Fe}_{2} \mathrm{O}_{3}$.

The pressure in the XPS analysis chamber was maintained at $1 \times 10^{-7} \mathrm{~Pa}$ throughout the measurements. The analyzed regions were $\mathrm{Fe} 2 \mathrm{p}_{3 / 2}, \mathrm{Fe} 2 \mathrm{p}_{1 / 2}, \mathrm{O} 1 \mathrm{~s}$, and $\mathrm{C} 1 \mathrm{~s}$. The binding energy (BE) scale of the spectrophotometer was calibrated using an $\mathrm{Au} 4 \mathrm{f}_{7 / 2}(84.0 \mathrm{eV}, \mathrm{BE})$ substrate. The full width at half-maximum (FWHM) obtained for the Ag $3 \mathrm{~d} 5 / 2(368.3 \mathrm{eV}$ $\mathrm{BE}$ ) line was $0.9 \mathrm{eV}$. High resolution spectra were recorded using $20 \mathrm{eV}$ pass energy. A Shirley background subtraction was made to obtain the XPS signal intensity.

SEM and TEM characterizations were carried out using Tescan Lyra 3 XMU and JEOL 2010 transmission electron microscope operating at $200 \mathrm{kV}$, respectively. In order to compare the suspension stability between specimens, $15 \mathrm{mg}$ of $\mathrm{CNF}$, oxidized carbon nanofibers, and $\mathrm{CNF} / \gamma-\mathrm{Fe}_{2} \mathrm{O}_{3}$ were dispersed in $10 \mathrm{ml}$ of deionized water via sonication for $20 \mathrm{~min}$ and upheld for $24 \mathrm{~h}$. The magnetic attraction of the $\mathrm{CNF} / \gamma-\mathrm{Fe}_{2} \mathrm{O}_{3}$ was tested by placing a magnet close to a glass container with carbon nanomaterial.

\section{Results and Discussions}

EDXRF analysis results showed a significant difference in terms of iron content between the $\mathrm{CNF} / \gamma-\mathrm{Fe}_{2} \mathrm{O}_{3}$ and the rest of the samples. The $\mathrm{CNF} / \gamma-\mathrm{Fe}_{2} \mathrm{O}_{3}$ presented an iron content of $86.91 \%$ mass percent, which represents an increase of $55 \%$ compared to the rest of the specimens. The increment of iron in the $\mathrm{CNF} / \gamma-\mathrm{Fe}_{2} \mathrm{O}_{3}$ sample may be attributed to the presence of iron (III) oxide $\left(\gamma-\mathrm{Fe}_{2} \mathrm{O}_{3}\right)$. Figure 1 shows the elemental analysis results for the CNF, oxidized CNF, and $\mathrm{CNF} / \gamma-\mathrm{Fe}_{2} \mathrm{O}_{3}$ specimens.

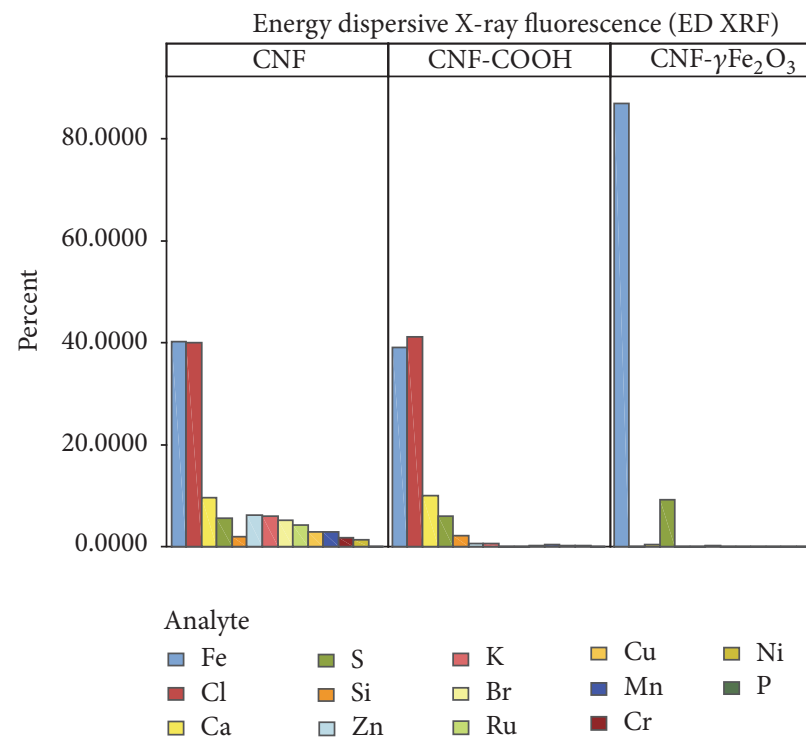

FIGURE 1: Elemental analysis of carbon nanomaterials.

SEM/EDS techniques were used to compare the morphology and composition of CNF, oxidized CNF, and $\mathrm{CNF} / \gamma-\mathrm{Fe}_{2} \mathrm{O}_{3}$ specimens. The magnetic carbon nanofibers exhibit "cumulus" seen as bright spots in the SEM image (Figure 2(c)), while the other two types of fibers (Figures 2(a) and 2(b)) do not present this feature. The EDS chemical analysis performed during the SEM analysis of CNF and oxidized CNF (Figures 2(a) and 2(b)) presents a high peak corresponding to carbon and a small additional peak related to oxygen. The spectrum obtained from cumulus region in the $\mathrm{CNF} / \gamma-\mathrm{Fe}_{2} \mathrm{O}_{3}$ specimen (Figure 2(c)) showed, in addition to the $\mathrm{C}$ peak, the presence of well-defined peaks of $\mathrm{O}, \mathrm{Fe}$, $\mathrm{Na}, \mathrm{P}$, and $\mathrm{S}$. Table 2 gives results for the mass percentage of elements obtained in four different regions on the maghemite carbon nanofiber, marked with circles in Figure 2(c). Higher iron and oxygen concentrations were found in the cumulus regions, 2 and 4, with values of 45.17, 27.33\%, 51.32, and $27.84 \%$, respectively. The results presented in Table 2 may be explained by presence of iron (III) oxide $\left(\gamma-\mathrm{Fe}_{2} \mathrm{O}_{3}\right)$. Indeed, $\gamma-\mathrm{Fe}_{2} \mathrm{O}_{3}$ has a molar mass of $159.687 \mathrm{~g} / \mathrm{mol}$ of which $30 \%$ is due to oxygen and $70 \%$ to iron with iron to oxygen mass percentage ratio $(\mathrm{O}: \mathrm{Fe})$ of 0.43 . The results obtained by EDS for the mean mass percentage of oxygen and iron, 19.947 and $37.435 \%$, give a value of 0.53 for the $(\mathrm{O}: \mathrm{Fe})$ ratio, similar to 


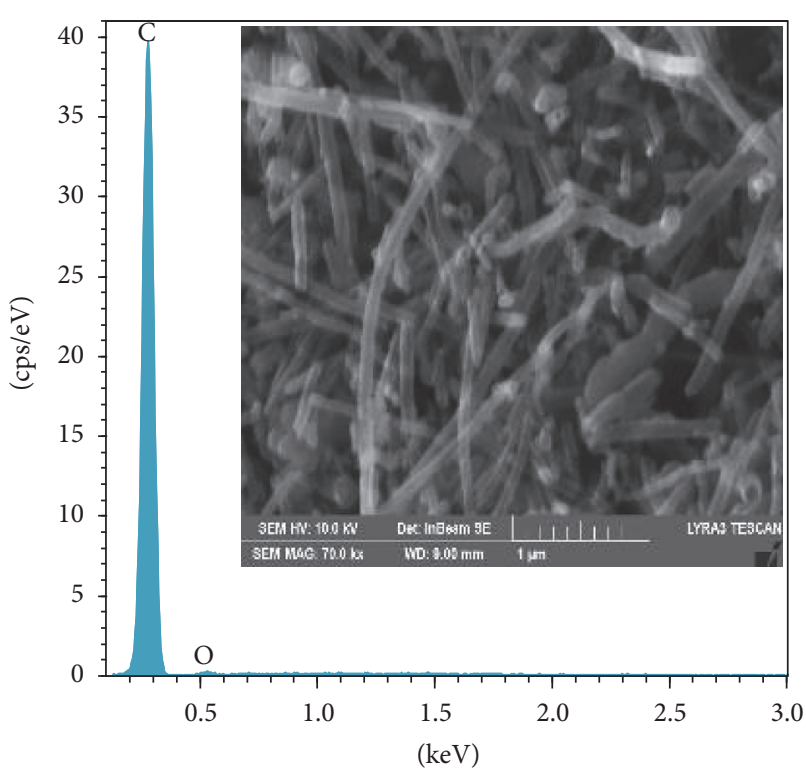

(a)

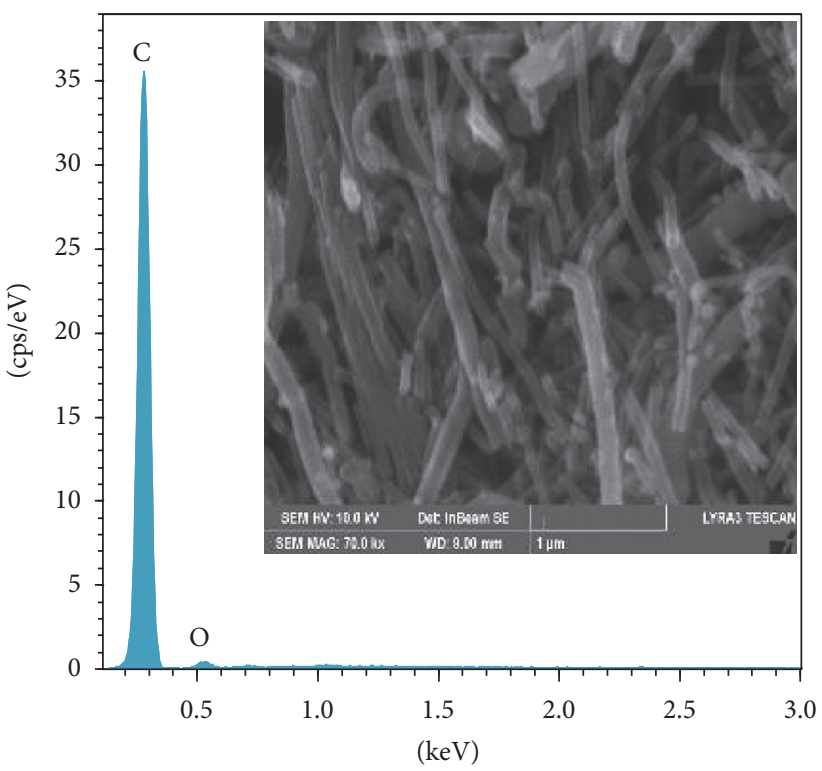

(b)

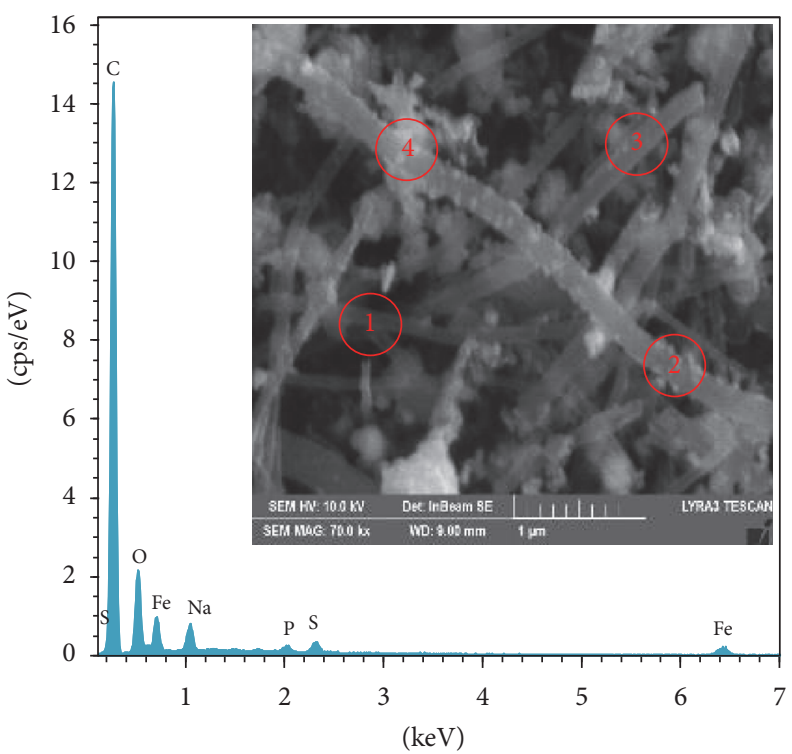

(c)

Figure 2: (a) EDS analysis of CNF specimen, (b) oxidized CNFs, and (c) maghemite carbon nanofiber $\left(\mathrm{CNF} / \gamma\right.$-Fe $\left.{ }_{2} \mathrm{O}_{3}\right)$. Insets show SEM images of analyzed area, respectively.

that of $\gamma-\mathrm{Fe}_{2} \mathrm{O}_{3}$. The small percent of $\mathrm{Na}, \mathrm{P}$, and $\mathrm{S}$ detected in the $\mathrm{CNF} / \gamma-\mathrm{Fe}_{2} \mathrm{O}_{3}$ specimen is a result of the chemicals used in the $\mathrm{CNF} / \gamma-\mathrm{Fe}_{2} \mathrm{O}_{3}$ synthesis. EDS analysis showed the presence of iron in the $\mathrm{CNF} / \gamma-\mathrm{Fe}_{2} \mathrm{O}_{3}$ specimen, which was not observed in the rest of the specimens (see Figure 2). SEM images of the magnetic carbon nanofiber specimen exhibited "cumulus" on the surface (see Figure 2(c)) in which the EDS data were collected. It was found that the highest mass percentage of iron comes from the cumulus areas, which may be explained by the presence of iron (III) oxide $(\gamma$ $\mathrm{Fe}_{2} \mathrm{O}_{3}$ ).

Additional information for the CNFs and $\mathrm{CNFs} / \gamma$ $\mathrm{Fe}_{2} \mathrm{O}_{3}$ morphology was obtained by transmission electron microscopy (Figure 3). The image of the CNF specimen (Figure 3(a)) shows bare fiber walls without attached particles, in agreement with the specification of the starting material. In contrast, the $\mathrm{CNFs} / \gamma-\mathrm{Fe}_{2} \mathrm{O}_{3}$ specimen exhibits high concentration of cumulus attached to the inner and outer surface of the walls (Figure 3(b)). The inset in Figure 3(b) shows a high resolution TEM image of the $\mathrm{CNF} / \gamma-\mathrm{Fe}_{2} \mathrm{O}_{3}$ specimen. Randomly distributed cumulus of maghemite nanoparticles is clearly seen. The $\gamma-\mathrm{Fe}_{2} \mathrm{O}_{3}$ nanoparticles are distributed very close to each other due to the absence of reactive species used during the functionalization process which can cause electrostatic interactions. From the high resolution image the outer diameter of the CNF was determined to be about $70 \mathrm{~nm}$, 


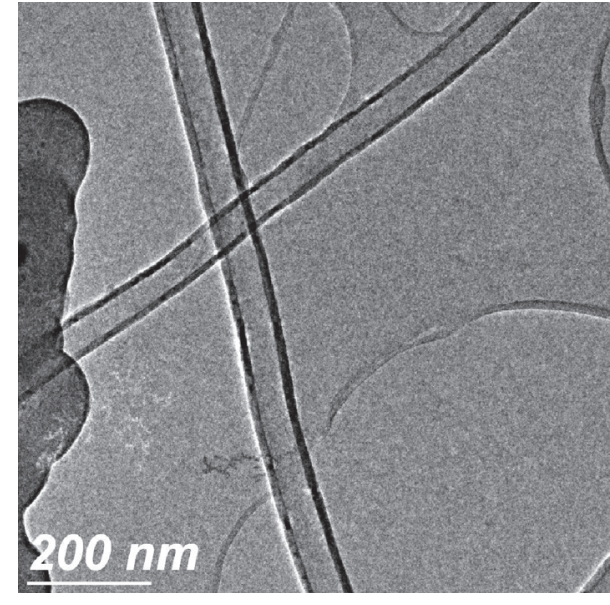

(a)

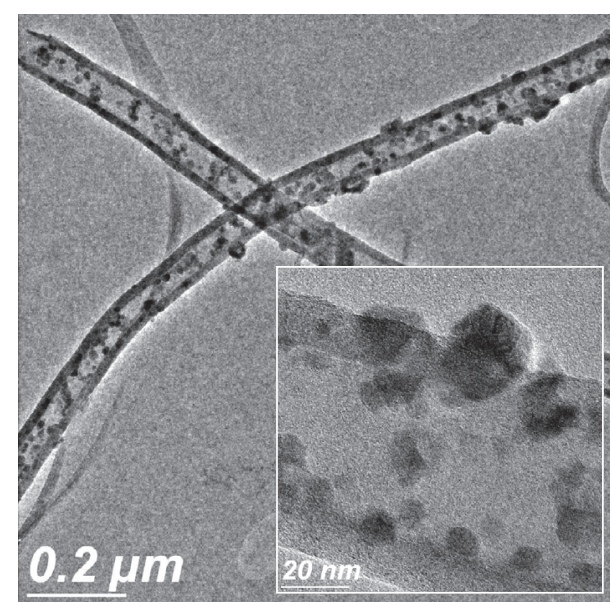

(b)

Figure 3: (a) TEM image of CNF specimen and (b) maghemite CNF $\left(\mathrm{CNF} / \gamma-\mathrm{Fe}_{2} \mathrm{O}_{3}\right)$. Inset in (b) shows high resolution image of CNF/ $\gamma$ $\mathrm{Fe}_{2} \mathrm{O}_{3}$.

close to the specification value, the wall thickness was in the $13-15 \mathrm{~nm}$ range, and the maghemite nanoparticle size was $10 \pm 1.5 \mathrm{~nm}$ in the inner space of the hollow CNFs and up to $22 \mathrm{~nm}$ for the cumulus on the external surface [34-36].

XPS spectra were obtained on CNF, functionalized CNF, and $\mathrm{CNF} / \gamma-\mathrm{Fe}_{2} \mathrm{O}_{3}$ specimens in order to determine the chemical composition and the degree of oxidation, iron (II) or iron (III), of the iron oxide nanoparticles. Figure 4(a) shows XPS survey spectra of the three materials with characteristic peaks for $\mathrm{Fe} 2 \mathrm{p}_{3 / 2}$ and $\mathrm{Fe} 2 \mathrm{p}_{1 / 2}$ in addition to carbon $\mathrm{C} 1 \mathrm{~s}(285 \mathrm{eV})$ and oxygen $\mathrm{O}$ 1s. The positions of the Fe $2 \mathrm{p}_{1 / 2}$ and $\mathrm{Fe} 2 \mathrm{p}_{3 / 2}$ peaks, determined from the high resolution XPS spectrum (Figure 4(b)), were at 725 and $711 \mathrm{eV} \mathrm{BE}$, respectively, which are in good agreement with the values reported for $\gamma-\mathrm{Fe}_{2} \mathrm{O}_{3}$ in the literature [37-39]. High resolution spectra of the $\mathrm{O} 1 \mathrm{~s}$ peak are presented in Figure 4(c). The $\mathrm{O}$ 1s peak of the CNF material has a maximum at about $533 \mathrm{eV}$, which can be related to water absorption [40]. The functionalized CNF spectrum was deconvoluted in two peaks, at $533 \mathrm{eV}$ and at $531.2 \mathrm{eV}$, which corresponds to $\mathrm{OH}$ hydroxyl group [41]. The spectrum of $\mathrm{CNF} / \gamma-\mathrm{Fe}_{2} \mathrm{O}_{3}$ was deconvoluted in three peaks, the water related and hydroxyl group peaks and one additional peak resulting from oxygen in iron oxide at $530.1 \mathrm{eV}$ [42-44]. The positions of the $\mathrm{Fe} 2 \mathrm{p}_{1 / 2}$ and $\mathrm{Fe}$ $2 \mathrm{p}_{3 / 2}$ peaks support the formation of $\gamma-\mathrm{Fe}_{2} \mathrm{O}_{3}$ in the carbon nanohybrid material.

The three types of specimens were characterized by Xray diffraction technique. The specimen with iron oxide nanoparticles (curve (3), Figure 5) presents in addition to the ( $\left.\begin{array}{lll}0 & 0 & 2\end{array}\right)$ peak of CNF $[45,46]$ some characteristic peaks for both maghemite and magnetite materials. The XRD spectra do not provide direct evidence for the oxide phase since the intensity of the maghemite specific peaks $(210)$ at $23.77^{\circ}$ and $\left(\begin{array}{lll}2 & 1 & 1\end{array}\right)$ at $26.10^{\circ}$ is very low. Moreover, the second peak is partially covered by the CNF $\left(\begin{array}{lll}0 & 0 & 2\end{array}\right)$ peak at $26^{\circ}$. An indirect indication can be obtained from the shape of the high-angle peaks (5 11 1) and (4 40 ). It has been shown by Kim et al. [47] that these peaks are doublets in case of mixture of magnetite $\left(\mathrm{Fe}_{3} \mathrm{O}_{4}\right)$ and maghemite $\left(\gamma-\mathrm{Fe}_{2} \mathrm{O}_{3}\right)$ phases; for example, the maximum of the (5 1 1) peak varies from $57^{\circ}$ for pure $\mathrm{Fe}_{3} \mathrm{O}_{4}$ to $57.3^{\circ}$ for pure $\gamma-\mathrm{Fe}_{2} \mathrm{O}_{3}$. For $\mathrm{Fe}_{3} \mathrm{O}_{4} / \mathrm{Fe}_{2} \mathrm{O}_{3}$ mixture, the intensity of each of these peaks varies, depending on the concentration of the corresponding oxide. The experimental data of each of the $\left(\begin{array}{lll}5 & 1 & 1\end{array}\right)$ and $\left(\begin{array}{lll}4 & 0 & 0\end{array}\right)$ peaks in Figure 5 were successfully fitted with a single symmetric peak with maximum at $57.3^{\circ}$ and $62.8^{\circ}$, respectively, which is an indirect indication for formation of $\gamma-\mathrm{Fe}_{2} \mathrm{O}_{3}$ attached to the CNF during the synthesis. The inset figure in Figure 5 shows the fitting of the (llll 00 ) peak.

Figure 6 shows the Raman spectra of CNF, CNF-COOH, and CNF with iron oxide nanoparticles. The spectra of the first two materials display only two broad peaks with maximums at $\sim 1315$ and $1595 \mathrm{~cm}^{-1}$ corresponding to the two main bands of CNF: the disorder induced D band and the graphite mode $\mathrm{G}$ band $[45,48]$. In contrast, the specimen with iron oxide nanoparticles shows five additional peaks, at $\sim 220$, $290,400,485$, and $598 \mathrm{~cm}^{-1}$. Peaks, with positions close to the last two bands, have been observed in the spectrum of highly crystalline and monodisperse maghemite nanocrystallites with size of $11 \mathrm{~nm}$ [49]; the average size of the synthetized nanoparticles in this work was about $10 \mathrm{~nm}$. The other three peaks (curve (3), Figure 6) are characteristic for hematite, 225,291 , and $411 \mathrm{~cm}^{-1}$ [50]. It has been shown that very low laser power $(<1 \mathrm{~mW})$ has to be used in Raman measurements in order to avoid transformation of maghemite to hematite $[50,51]$. The measured spectrum of the sample with iron oxide nanoparticles may be explained by the laser power used in these experiments, $12 \mathrm{~mW}$, which most likely caused transformation of the major part of maghemite to hematite.

The synthesis of $\mathrm{CNF} / \gamma-\mathrm{Fe}_{2} \mathrm{O}_{3}$ leads to an increase in the hydrophilicity of the CNF. Before synthesis, the dispersion of the $\mathrm{CNF}$ in aqueous media was very poor, while after 

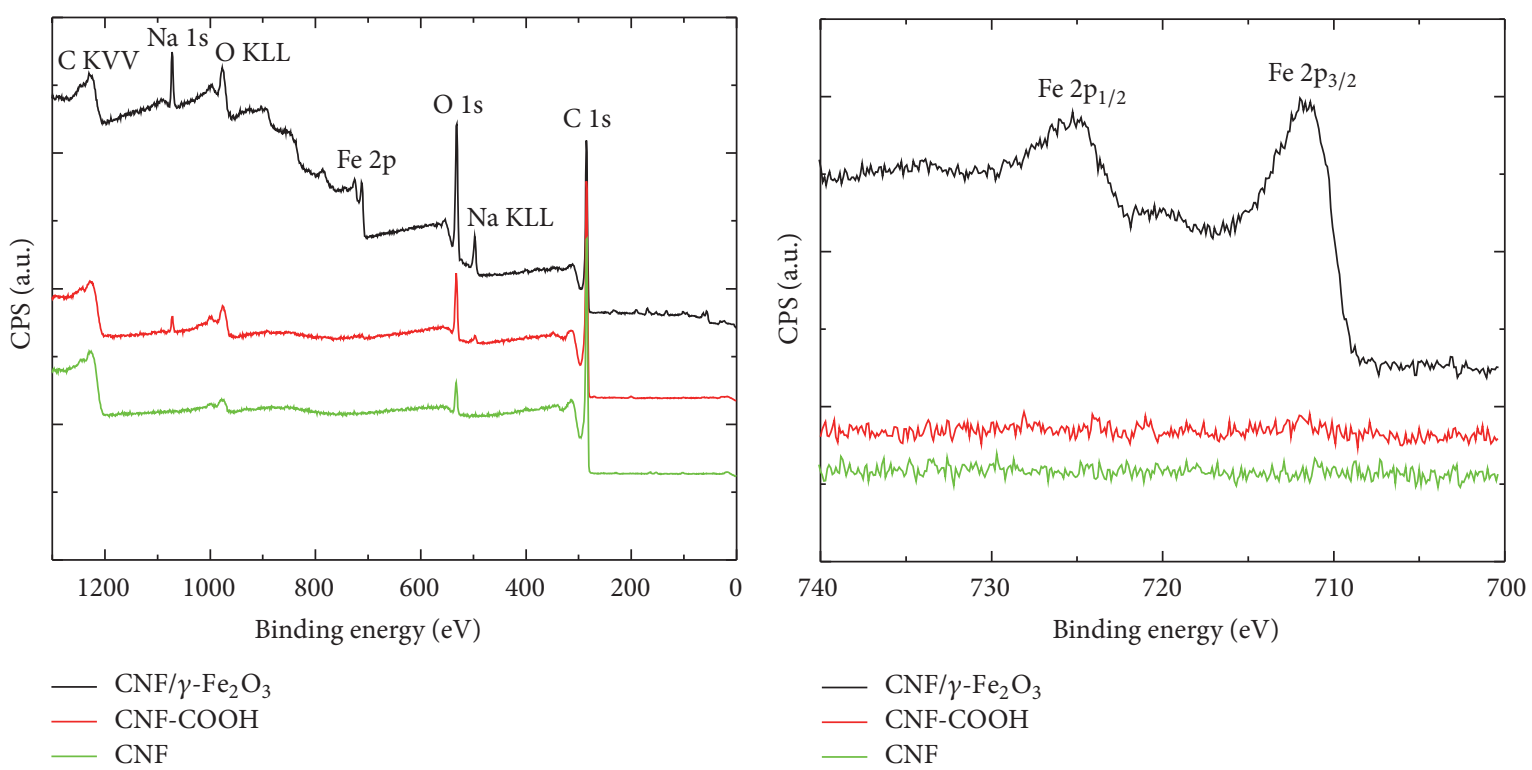

(a)

(b)

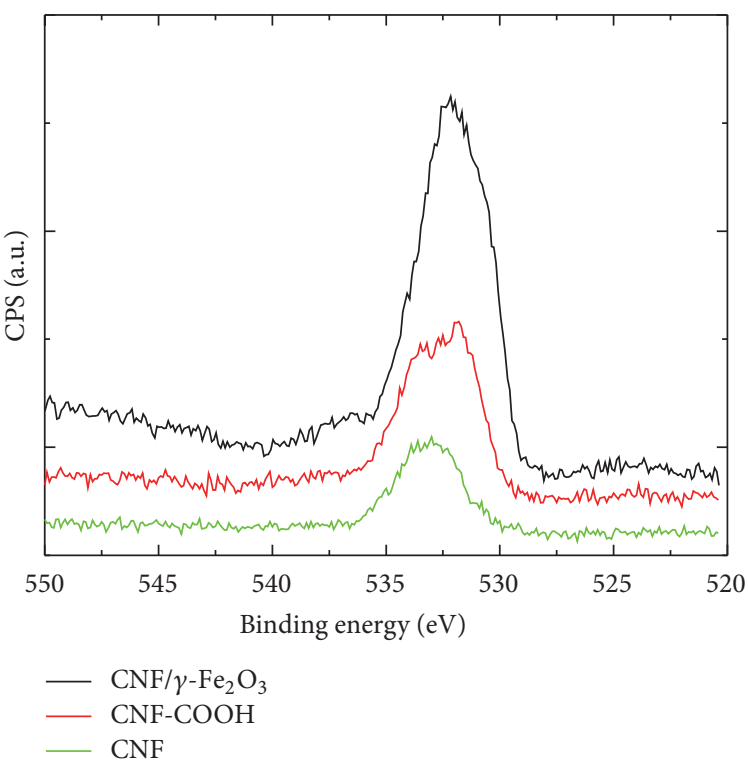

(c)

Figure 4: (a) XPS survey spectra of CNF/ $\gamma$ - $\mathrm{Fe}_{2} \mathrm{O}_{3}, \mathrm{CNF}-\mathrm{COOH}$ and CNF; high resolution XPS spectra, showing (b) Fe $2 \mathrm{p}_{1 / 2}$ and Fe $2 \mathrm{p}_{3 / 2}$ regions and (c) $\mathrm{O}$ 1s region.

synthesis it improved significantly (see Figure 7(a)). This improvement in dispersion is associated with the functionalization procedure used during the synthesis of the $\mathrm{CNF} / \gamma$ $\mathrm{Fe}_{2} \mathrm{O}_{3}$ material. However, the $\mathrm{CNF}-\mathrm{COOH}$ sample showed a much better dispersion than $\mathrm{CNF} / \gamma-\mathrm{Fe}_{2} \mathrm{O}_{3}$ after $24 \mathrm{~h}$, which may be due to the molecular weight increase after the inclusion of $\gamma-\mathrm{Fe}_{2} \mathrm{O}_{3}$ to the CNF (see Figure 7(b)).

The three carbon nanofiber materials (CNF, CNF$\mathrm{COOH}$, and $\mathrm{CNF} / \gamma-\mathrm{Fe}_{2} \mathrm{O}_{3}$ ) were exposed to a magnetic field created by a commercial magnet. The $\mathrm{CNF} / \gamma-\mathrm{Fe}_{2} \mathrm{O}_{3}$ specimen showed magnetic properties at room temperature in contrast to the rest of the specimens, which may be explained by the presence of $\gamma-\mathrm{Fe}_{2} \mathrm{O}_{3}$ in the nanohybrid material (see Figure 8).

\section{Conclusions}

Synthesis of carbon nanofibers functionalized with maghemite nanoparticles via a modified sol-gel technique was successfully performed. The formation of $\gamma-\mathrm{Fe}_{2} \mathrm{O}_{3}$ was confirmed by EDXRF, EDS, XPS, XRD, and Raman spectroscopy. In particular, the iron content in the CNF and $\mathrm{CNF}-\mathrm{COOH}$ determined using EDXRF was $40 \%$ and $39 \%$, respectively. According to the supplier's information, 


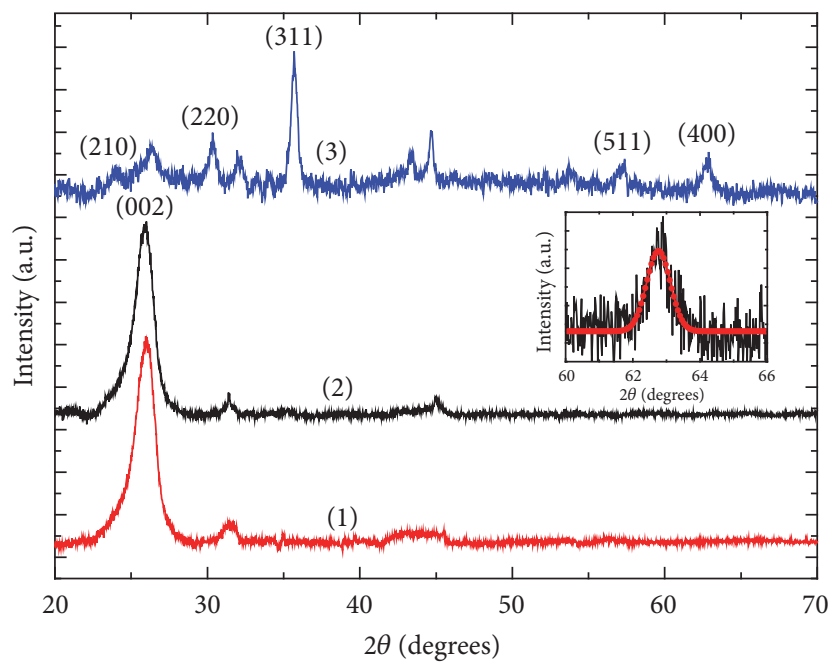

FIGURE 5: XRD spectra of CNF (curve (1)), CNF-COOH (curve (2)), and CNF/ $\gamma-\mathrm{Fe}_{2} \mathrm{O}_{3}$ (curve (3)). The inset shows fitting of the (4 00 ) peak with a single symmetric peak with maximum at $62.8^{\circ}$.

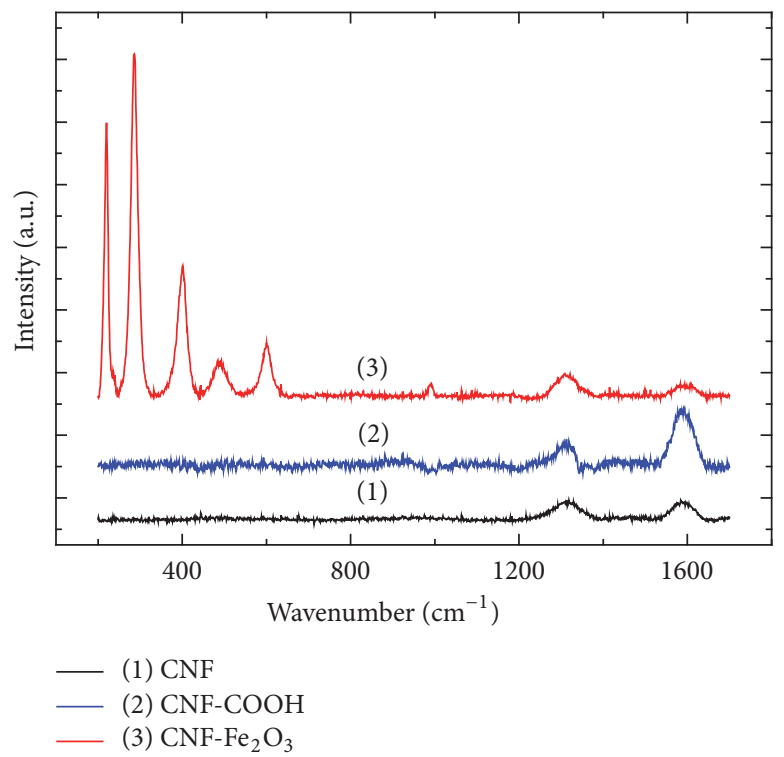

Figure 6: Raman spectra of CNF (curve (1)), CNF-COOH (curve (2)), and CNF/ $\gamma-\mathrm{Fe}_{2} \mathrm{O}_{3}$ (curve (3)).

the CNF material contains iron at a concentration of $<14000 \mathrm{ppm}$. However, after the synthesis process the iron content in the nanohybrid material increased up to about $87 \%$, more than double than the concentration found in the $\mathrm{CNF}$ and $\mathrm{CNF}-\mathrm{COOH}$ specimens.

One of the important physical properties of $\gamma-\mathrm{Fe}_{2} \mathrm{O}_{3}$ is its high magnetic permeability. The results of the magnetism experiment showed that only the nanohybrid material reacted to the presence of a magnetic field, which is another indication for the formation of $\gamma-\mathrm{Fe}_{2} \mathrm{O}_{3}$. From these results we can conclude that there was a high efficiency of the functionalization methodology applied. The synthesized $\mathrm{CNF} / \gamma$ $\mathrm{Fe}_{2} \mathrm{O}_{3}$ material shows improved dispersion in aqueous media and magnetic properties at room temperature, which make it a promising candidate for fabrication of composite structures with improved characteristics, high temperature conductive coatings, or biosensors.

The morphology obtained by SEM and TEM indicates formation of maghemite nanoparticles with an average size of $10 \pm 0.5 \mathrm{~nm}$ homogeneously distributed on the inner and outer surfaces of the functionalized carbon nanofibers. The EDS analysis performed on the cumulus areas gave the highest mass percentage of iron. XPS results support the formation of $\gamma-\mathrm{Fe}_{2} \mathrm{O}_{3}$ in the carbon nanohybrid material, showing the characteristics peaks for Fe $2 \mathrm{p}_{1 / 2}$ and Fe $2 \mathrm{p}_{3 / 2}$ at 725 and $711 \mathrm{eV} \mathrm{BE}$, respectively. $\mathrm{XRD}$ results indicate single symmetric 511 and 400 peaks with maximums at $57.3^{\circ}$ and $62.8^{\circ}$, respectively, supporting the formation of 


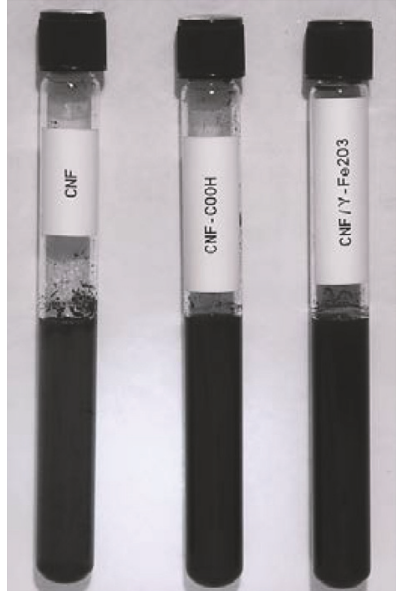

(a)

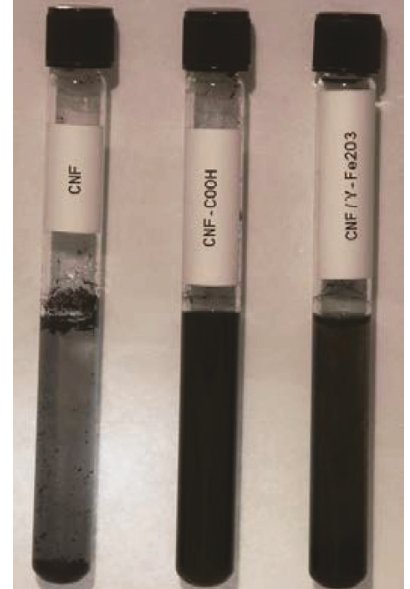

(b)

FIGURE 7: (a) Carbon nanomaterials just dispersed and (b) carbon nanomaterials after $24 \mathrm{~h}$.

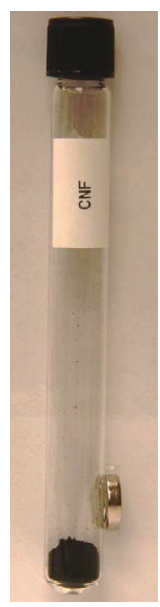

(a)

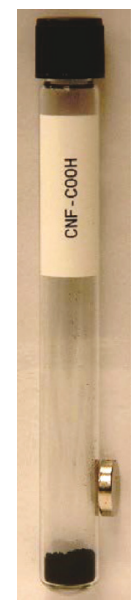

(b)

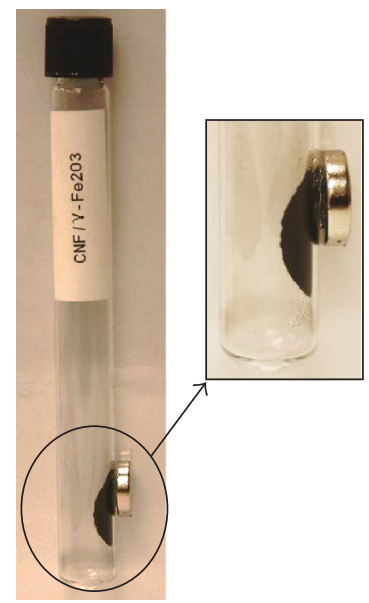

(c)

Figure 8: (a) CNF specimen, (b) oxidized CNF, and (c) maghemite carbon nanofiber $\left(\mathrm{CNF} / \gamma-\mathrm{Fe}_{2} \mathrm{O}_{3}\right)$.

$\gamma-\mathrm{Fe}_{2} \mathrm{O}_{3}$. Raman spectroscopy showed essential differences between the CNF, CNF-COOH, and $\mathrm{CNF} / \gamma-\mathrm{Fe}_{2} \mathrm{O}_{3}$ samples. The characteristic peaks of graphite $(\mathrm{G})$ band and disorder induced (D) band were observed in the spectra of all samples. However, the $\mathrm{CNF} / \gamma-\mathrm{Fe}_{2} \mathrm{O}_{3}$ spectrum showed five additional peaks in the range of $200-600 \mathrm{~cm}^{-1}$; two of them, at 485 and $598 \mathrm{~cm}^{-1}$, may be attributed to maghemite nanocrystallites with size of $\sim 10 \mathrm{~nm}$, the average size of the nanoparticles in this study.

One of the important physical properties of $\gamma-\mathrm{Fe}_{2} \mathrm{O}_{3}$ is its high magnetic permeability. The results of the magnetism experiment showed that only the nanohybrid material reacted to a magnetic field, which is another indication for $\gamma-\mathrm{Fe}_{2} \mathrm{O}_{3}$ formation. From these results we can conclude that there was a high efficiency of the functionalization methodology applied. The synthesized $\mathrm{CNF} / \gamma-\mathrm{Fe}_{2} \mathrm{O}_{3}$ material shows improved dispersion in aqueous media and magnetic properties at room temperature, which make it a promising candidate for fabrication of composite structures with improved characteristics, high temperature conductive coatings, or biosensors.

\section{Conflicts of Interest}

The authors declare no conflicts of interest.

\section{Acknowledgments}

The authors acknowledge the support of the Engineering Institute of the Autonomous University of Baja California (UABC), Mexico, and the National Center for Metallurgical Research (CENIM-CSIC), Spain, during the performance of this research. The authors are also thankful to the Center of Nanoscience and Nanotechnology of the National 
Autonomous University of Mexico (UNAM), for the help with XPS and TEM analysis. Finally, the authors are grateful to the National Council of Science and Technology of Mexico (CONACYT) for supporting this research through MYDCI Program Scholarship Grant (no. 257875).

\section{References}

[1] X.-L. Wang, I.-K. Oh, and J.-B. Kim, "Enhanced electromechanical performance of carbon nano-fiber reinforced sulfonated poly(styrene-b-[ethylene/butylene]-b-styrene) actuator," Composites Science and Technology, vol. 69, no. 13, pp. 2098-2101, 2009.

[2] J. H. Lehman, M. Terrones, E. Mansfield, K. E. Hurst, and V. Meunier, "Evaluating the characteristics of multiwall carbon nanotubes," Carbon, vol. 49, no. 8, pp. 2581-2602, 2011.

[3] M. H. Al-Saleh and U. Sundararaj, "Review of the mechanical properties of carbon nanofiber/polymer composites," Composites Part A: Applied Science and Manufacturing, vol. 42, no. 12, pp. 2126-2142, 2011.

[4] E. Enríquez, J. de Frutos, J. F. Fernández, and M. A. de la Rubia, "Conductive coatings with low carbon-black content by adding carbon nanofibers," Composites Science and Technology, vol. 93, pp. 9-16, 2014.

[5] S. Bal, S. S. Samal, and U. K. Mohanty, "Mechanical and microstructural analysis of carbon nanotube composites pretreated at different temperatures," American Journal of Materials Science, vol. 1, no. 1, pp. 5-11, 2011.

[6] D. Zhou, E. V. Anoshkina, L. Chow, and G. Chai, "Synthesis of carbon nanotubes by electrochemical deposition at room temperature," Carbon, vol. 44, no. 5, pp. 1013-1016, 2006.

[7] C. L. Cheung, A. Kurtz, H. Park, and C. M. Lieber, "Diametercontrolled synthesis of carbon nanotubes," The Journal of Physical Chemistry B, vol. 106, no. 10, pp. 2429-2433, 2002.

[8] M. V. Reddy, G. V. Subba Rao, and B. V. R. Chowdari, "Metal oxides and oxysalts as anode materials for Li ion batteries," Chemical Reviews, vol. 113, no. 7, pp. 5364-5457, 2013.

[9] Y. Wu, P. Zhu, M. V. Reddy, B. V. R. Chowdari, and S. Ramakrishna, "Maghemite nanoparticles on electrospun CNFs template as prospective lithium-ion battery anode," ACS Applied Materials \& Interfaces, vol. 6, no. 3, pp. 1951-1958, 2014.

[10] Y. Wu, M. V. Reddy, B. V. R. Chowdari, and S. Ramakrishna, "Long-term cycling studies on electrospun carbon nanofibers as anode material for lithium ion batteries," ACS Applied Materials \& Interfaces, vol. 5, no. 22, pp. 12175-12184, 2013.

[11] A. S. Hameed, M. V. Reddy, B. V. R. Chowdari, and J. J. Vittal, "Preparation of rGO-wrapped magnetite nanocomposites and their energy storage properties," RSC Advances, vol. 4, no. 109, pp. 64142-64150, 2014.

[12] S. Petnikota, H. Maseed, V. V. S. S. Srikanth et al., "Experimental Elucidation of a Graphenothermal Reduction Mechanism of $\mathrm{Fe}_{2} \mathrm{O}_{3}$ : An Enhanced Anodic Behavior of an Exfoliated Reduced Graphene Oxide/ $\mathrm{Fe}_{3} \mathrm{O}_{4}$ Composite in Li-Ion Batteries," The Journal of Physical Chemistry C, vol. 121, no. 7, pp. 3778-3789, 2017.

[13] M. V. Reddy, C. T. Cherian, K. Ramanathan et al., "Molten synthesis of $\mathrm{ZnO} . \mathrm{Fe}_{3} \mathrm{O}_{4}$ and $\mathrm{Fe}_{2} \mathrm{O}_{3}$ and its electrochemical performance," Electrochimica Acta, vol. 118, pp. 75-80, 2014.

[14] C. T. Cherian, J. Sundaramurthy, M. Kalaivani et al., "Electrospun $\alpha-\mathrm{Fe}_{2} \mathrm{O}_{3}$ nanorods as a stable, high capacity anode material for Li-ion batteries," Journal of Materials Chemistry, vol. 22, no. 24, pp. 12198-12204, 2012.
[15] M. V. Reddy, T. Yu, C.-H. Sow et al., " $\alpha-\mathrm{Fe}_{2} \mathrm{O}_{3}$ nanoflakes as an anode material for li-ion batteries," Advanced Functional Materials, vol. 17, no. 15, pp. 2792-2799, 2007.

[16] J. Jia, X. Sun, X. Lin, X. Shen, Y.-W. Mai, and J.-K. Kim, "Exceptional electrical conductivity and fracture resistance of 3D interconnected graphene foam/epoxy composites," ACS Nano, vol. 8, no. 6, pp. 5774-5783, 2014.

[17] C. Lake and P. Lake, "Carbon nanofiber multifunctional mat," in Nanotube Superfiber Materials Changing Engineering Design, M. Schulz, V. Shanov, and Z. Yin, Eds., pp. 313-331, William Andrew Applied Science Publishers, Waltham, Massachusetts, Mass, USA, 1st edition, 2014.

[18] I. Kang, Y. Y. Heung, J. H. Kim et al., "Introduction to carbon nanotube and nanofiber smart materials," Composites Part B: Engineering, vol. 37, no. 6, pp. 382-394, 2006.

[19] B. M. Tyson, R. K. Abu Al-Rub, A. Yazdanbakhsh, and Z. Grasley, "A quantitative method for analyzing the dispersion and agglomeration of nano-particles in composite materials," Composites Part B: Engineering, vol. 42, no. 6, pp. 1395-1403, 2011.

[20] K. A. Wepasnick, B. A. Smith, J. L. Bitter, and D. H. Fairbrother, "Chemical and structural characterization of carbon nanotube surfaces," Analytical and Bioanalytical Chemistry, vol. 396, no. 3, pp. 1003-1014, 2010.

[21] S. Bal, "Experimental study of mechanical and electrical properties of carbon nanofiber/epoxy composites," Materials and Corrosion, vol. 31, no. 5, pp. 2406-2413, 2010.

[22] C.-S. Lim, A. J. Rodriguez, M. E. Guzman, J. D. Schaefer, and B. Minaie, "Processing and properties of polymer composites containing aligned functionalized carbon nanofibers," Carbon, vol. 49, no. 6, pp. 1873-1883, 2011.

[23] I. Kim and R. Tannenbaum, "Magnetic carbon nanotubes: synthesis, characterization, and anisotropic electrical properties," in Electronic Properties of Carbon Nanotubes, pp. 33-55, InTech, Rijeka, Croatia, 2011.

[24] I. T. Kim, G. A. Nunnery, K. Jacob, J. Schwartz, X. Liu, and R. Tannenbaum, "Synthesis, characterization, and alignment of magnetic carbon nanotubes tethered with maghemite nanoparticles," The Journal of Physical Chemistry C, vol. 114, no. 15, pp. 6944-6951, 2010.

[25] I. T. Kim, A. Tannenbaum, and R. Tannenbaum, "Anisotropic conductivity of magnetic carbon nanotubes embedded in epoxy matrices," Carbon, vol. 49, no. 1, pp. 54-61, 2011.

[26] S. Wu, R. B. Ladani, J. Zhang et al., "Epoxy nanocomposites containing magnetite-carbon nanofibers aligned using a weak magnetic field," Polymer Journal, vol. 68, pp. 25-34, 2015.

[27] H. Varela-Rizo, S. Bittolo-Bon, I. Rodriguez-Pastor, L. Valentini, and I. Martin-Gullon, "Processing and functionalization effect in CNF/PMMA nanocomposites," Composites Part A: Applied Science and Manufacturing, vol. 43, no. 4, pp. 711-721, 2012.

[28] Z. Zhao, Z. Yang, Y. Hu, J. Li, and X. Fan, "Multiple functionalization of multi-walled carbon nanotubes with carboxyl and amino groups," Applied Surface Science, vol. 276, pp. 476-481, 2013.

[29] M. I. Barrena, J. M. Gómez De Salazar, A. Soria, and R. Cañas, "Improved of the wear resistance of carbon nanofiber/epoxy nanocomposite by a surface functionalization of the reinforcement," Applied Surface Science, vol. 289, pp. 124-128, 2014.

[30] A. G. Osorio, I. C. L. Silveira, V. L. Bueno, and C. P. Bergmann, " $\mathrm{H}_{2} \mathrm{SO}_{4} / \mathrm{HNO}_{3} / \mathrm{HCl}$-Functionalization and its effect on dispersion of carbon nanotubes in aqueous media," Applied Surface Science, vol. 255, no. 5, pp. 2485-2489, 2008. 
[31] J. Zhang, T. Lin, and X. Wang, "Carbon and polymer nanofiber reinforcements in polymer matrix composites: processing and applications," in Functional nanofibers and their applications, pp. 55-70, Woodhead, Philadelphia, Pennsylvania, Pa, USA, 2012.

[32] S. G. Prolongo, M. Burón, M. R. Gude, R. Chaos-Morán, M. Campo, and A. Ureña, "Effects of dispersion techniques of carbon nanofibers on the thermo-physical properties of epoxy nanocomposites," Composites Science and Technology, vol. 68, no. 13, pp. 2722-2730, 2008.

[33] Y. Harel, S. Azoubel, S. Magdassi, and J.-P. Lellouche, "A dispersability study on poly(thiophen-3-yl-acetic acid) and PEDOT multi-walled carbon nanotube composites using an analytical centrifuge," Journal of Colloid and Interface Science, vol. 390, no. 1, pp. 62-69, 2013.

[34] K. Safarova, A. Dvorak, R. Kubinek, M. Vujtek, and A. Rek, "Usage of AFM, SEM and TEM for the research of carbon nanotubes," in Modern Research and Educational Topics in Microscopy, vol. 5, pp. 513-519, Formatex, Bandajoz, Spain, 2007.

[35] G. Woehrle, J. Hutchinson, S. Ozkar, and R. Finke, "Analysis of nanoparticle transmission electron microscopy data using a public- domain image-processing program, image," Turkish Journal of Chemistry, vol. 30, pp. 1-13, 2006.

[36] F. Solá, Z. H. Xia, M. Lebrón-Colón, and M. A. Meador, "Transmission electron microscopy of single wall carbon nanotube/polymer nanocomposites: a first-principles study," Physica Status Solidi - Rapid Research Letters, vol. 6, no. 8, pp. 349351, 2012.

[37] H. Cui, Y. Liu, and W. Ren, "Structure switch between $\alpha$ $\mathrm{Fe} 2 \mathrm{O} 3, \gamma-\mathrm{Fe}_{2} \mathrm{O}_{3}$ and $\mathrm{Fe}_{3} \mathrm{O}_{4}$ during the large scale and low temperature sol-gel synthesis of nearly monodispersed iron oxide nanoparticles," Advanced Powder Technology, vol. 24, no. 1, pp. 93-97, 2013.

[38] W. Wu, X. H. Xiao, S. F. Zhang et al., "Synthesis and magnetic properties of maghemite $\left(\gamma-\mathrm{Fe}_{2} \mathrm{O}_{3}\right)$ short-nanotubes," Nanoscale Research Letters, vol. 5, no. 9, pp. 1474-1479, 2010.

[39] Y. Lu, Y. Yin, B. T. Mayers, and Y. Xia, "Modifying the surface properties of superparamagnetic iron oxide nanoparticles through a sol-gel approach," Nano Letters, vol. 2, no. 3, pp. 183186, 2002.

[40] D. Rosenthal, M. Ruta, R. Schlögl, and L. Kiwi-Minsker, "Combined XPS and TPD study of oxygen-functionalized carbon nanofibers grown on sintered metal fibers," Carbon, vol. 48, no. 6, pp. 1835-1843, 2010.

[41] T.-C. Lin, G. Seshadri, and J. A. Kelber, "A consistent method for quantitative XPS peak analysis of thin oxide films on clean polycrystalline iron surfaces," Applied Surface Science, vol. 119, no. 1-2, pp. 83-92, 1997.

[42] T. Yamashita and P. Hayes, "Analysis of XPS spectra of $\mathrm{Fe}^{2+}$ and $\mathrm{Fe}^{3+}$ ions in oxide materials," Applied Surface Science, vol. 254, no. 8, pp. 2441-2449, 2008.

[43] T. Fujii, F. M. F. De Groot, G. A. Sawatzky, F. C. Voogt, T. Hibma, and K. Okada, "In situ XPS analysis of various iron oxide films grown by $\mathrm{NO}_{2}$-assisted molecular-beam epitaxy," Physical Review B: Condensed Matter and Materials Physics, vol. 59, no. 4, pp. 3195-3202, 1999.

[44] M. V. Reddy, N. Sharma, S. Adams, R. P. Rao, V. K. Peterson, and B. V. R. Chowdari, "Evaluation of undoped and M-doped $\mathrm{TiO}$, where $\mathrm{M}=\mathrm{Sn}, \mathrm{Fe}, \mathrm{Ni} / \mathrm{Nb}, \mathrm{Zr}, \mathrm{V}$, and $\mathrm{Mn}$, for lithium-ion battery applications prepared by the molten-salt method," $R S C$ Advances, vol. 5, no. 37, pp. 29535-29544, 2015.

[45] J. I. Paredes, M. Burghard, A. Martínez-Alonso, and J. M. D. Tascón, "Graphitization of carbon nanofibers: visualizing the structural evolution on the nanometer and atomic scales by scanning tunneling microscopy," Applied Physics A: Materials Science \& Processing, vol. 80, no. 4, pp. 675-682, 2005.

[46] X. Du, H.-Y. Liu, G. Cai, Y.-W. Mai, and A. Baji, "Use of facile mechanochemical method to functionalize carbon nanofibers with nanostructured polyaniline and their electrochemical capacitance," Nanoscale Research Letters, vol. 7, article no. 111, pp. 1-10, 2012.

[47] W. Kim, C.-Y. Suh, S.-W. Cho et al., "A new method for the identification and quantification of magnetite-maghemite mixture using conventional X-ray diffraction technique," Talanta, vol. 94, pp. 348-352, 2012.

[48] Y. Wang, S. Serrano, and J. J. Santiago-Avilés, "Raman characterization of carbon nanofibers prepared using electrospinning," Synthetic Metals, vol. 138, no. 3, pp. 423-427, 2003.

[49] T. Hyeon, S. S. Lee, J. Park, Y. Chung, and H. B. Na, "Synthesis of highly crystalline and monodisperse maghemite nanocrystallites without a size-selection process," Journal of the American Chemical Society, vol. 123, no. 51, pp. 12798-12801, 2001.

[50] M. Hanesch, "Raman spectroscopy of iron oxides and (oxy)hydroxides at low laser power and possible applications in environmental magnetic studies," Geophysical Journal International, vol. 177, no. 3, pp. 941-948, 2009.

[51] D. L. A. De Faria, S. Venâncio Silva, and M. T. De Oliveira, "Raman microspectroscopy of some iron oxides and oxyhydroxides," Journal of Raman Spectroscopy, vol. 28, no. 11, pp. 873878, 1997. 

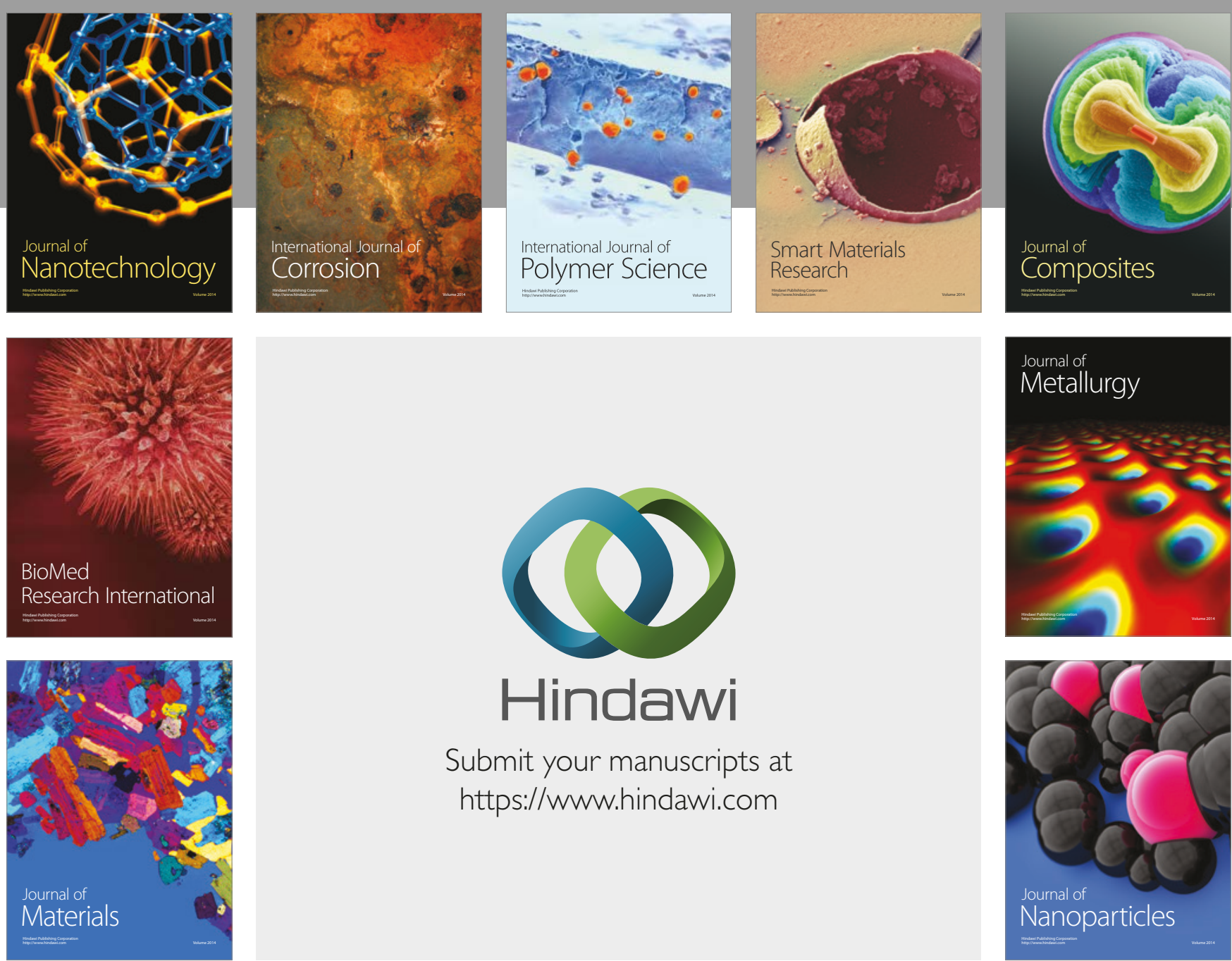

\section{Hindawi}

Submit your manuscripts at

https://www.hindawi.com
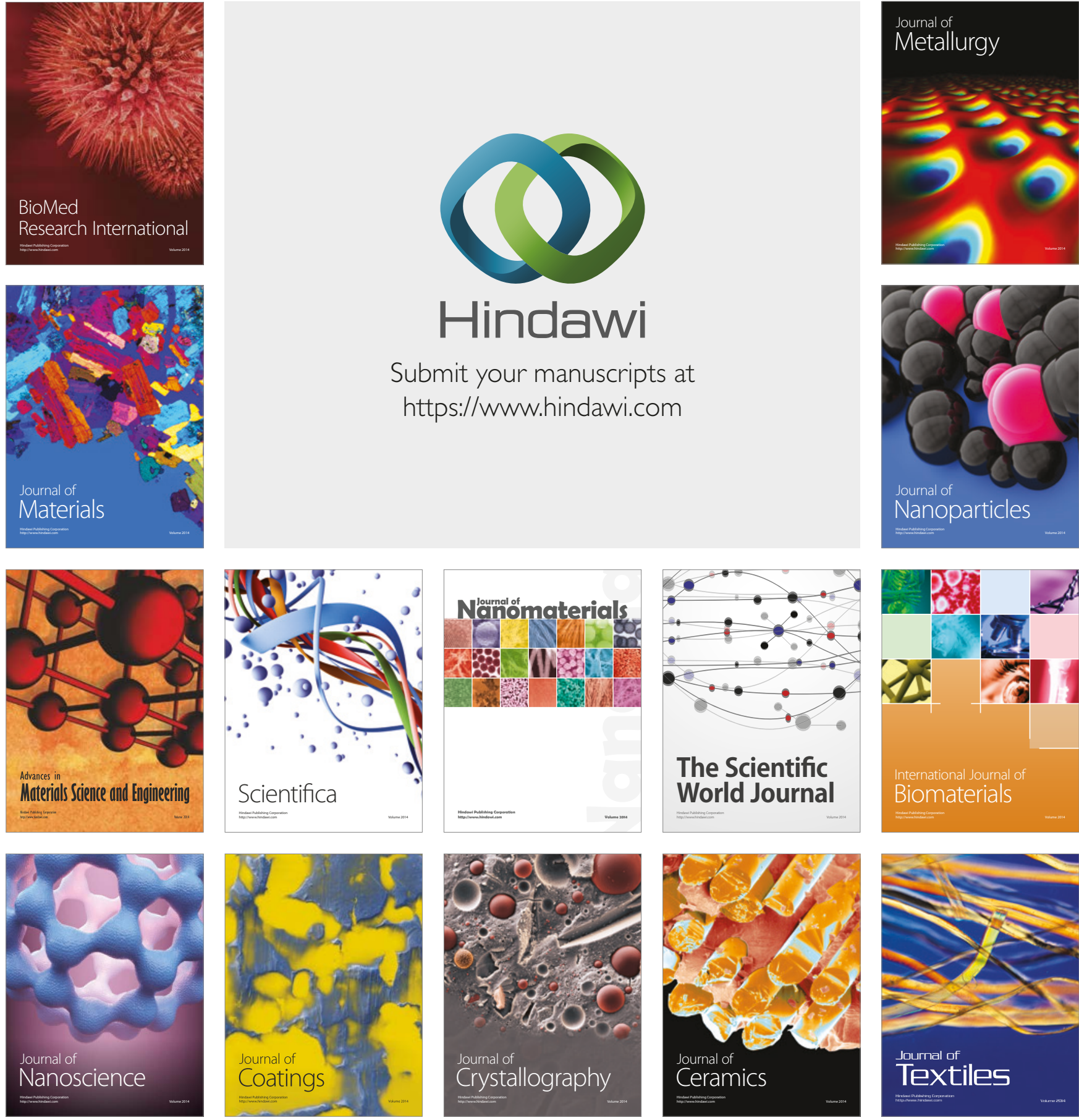

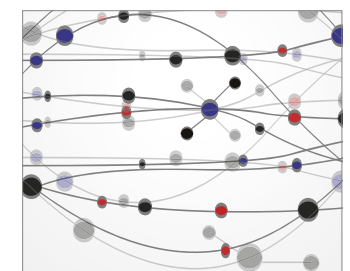

The Scientific World Journal
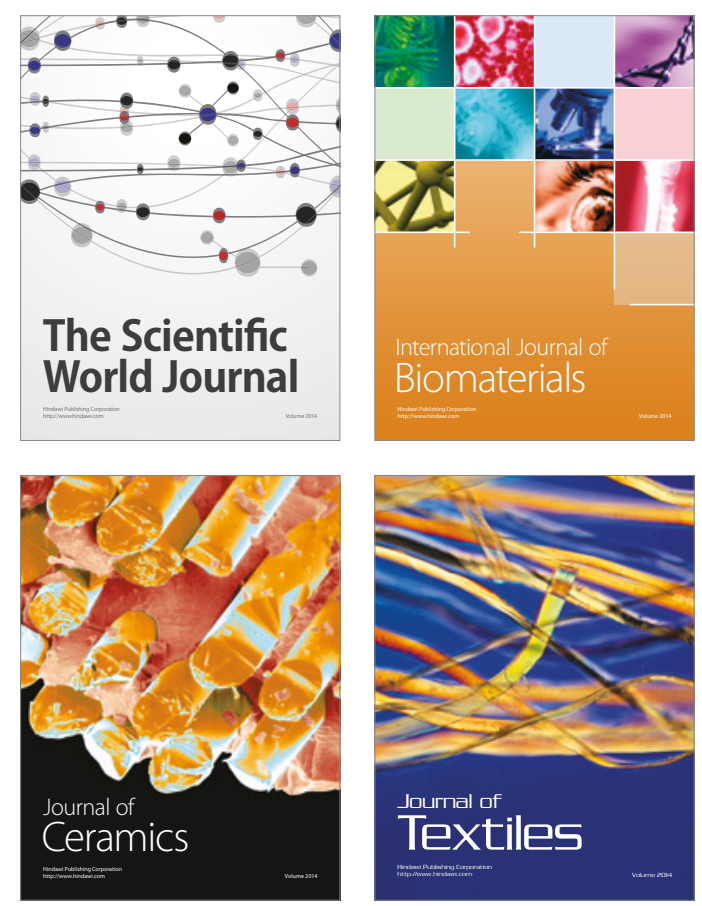